DOI: https://doi.org/10.24867/12DS06Markovic

\title{
VREDNOVANJE PREDLOGA REŠENJA ZA POBOLJŠANJE USLOVA ODVIJANJA SAOBRAĆAJA NA RASKRSNICAMA NA BULEVARU EVROPE, BULEVARU PATRIJARHA PAVLA I BULEVARU CARA LAZARA \\ EVALUATION OF SOLUTION PROPOSALS FOR TRAFFIC IMPROVEMENT FOR Boulevard Europe, Patrijarha Pavla Boulevard and Cara Lazara Boulevard INTERSECIONS
}

\author{
Jelena Marković, Fakultet tehničkih nauka, Novi Sad
}

\begin{abstract}
Oblast - SAOBRAĆAJ I TRANSPORT
Kratak sadržaj - U okviru ovog rada izvršena je analiza saobraćajnih tokova na odabranim raskrsnicama $i$ u okviru njih su utvrđene karakteristike saobraćajnog toka na raskrsnicama. Dati su predlozi rě̌enja poboljšanja uslova odvijanja saobraćaja. Urađeno je funkcionalno, ekološko $i$ ekonomsko vrednovanje predloženih rešenja, nakon čega se dobija optimalno rešenje, koje je predloženo za realizaciju.
\end{abstract}

Ključne reči: Saobraćaj, nivo usluge, vrednovanje

Abstract - Within this paper, the analysis of traffic flows at selected intersections was performed and within them the characteristics of traffic flow at intersections were determined. Proposals for solutions to improve traffic conditions are given. Functional, economic and ecological evaluation of the proposed solutions was done, after which the optimal solution was obtained, which was proposed for implementation.

Keywords: Traffic, LOS, evaluation

\section{UVOD}

Raskrsnice su čvorišta u kojima se vrši ukrštanje saobraćajnica istog ili različitog ranga. U putnoj uličnoj mreži raskrsnice predstavljaju važne tačke. Saobraćajni problemi u gradu su obično vezani za kapacitivne sposobnosti delova mreže.

Kada intezitet saobraćaja u vršnim časovima pređe objektivni kapacitet raskrsnice, vremenski gubici počinju da rastu, pa se iz tog razloga, način regulisanja saobraćaja na raskrsnicama menja.

U okviru ovog rada, izvršena je analiza uslova odvijanja saobraćaja na dve raskrsnice u Novom Sadu gde su dati predlozi rešenja poboljšanja uslova odvijanja saobraćaja. Prva raskrsnica je signalisana raskrsnica Bulevara cara Lazara i ulica Cara Dušana i Ive Andrića, dok je druga raskrsnica kružna i predstavlja mesto ukrštanja Bulevara cara Lazara, Bulevara Evrope, Bulevara patrijarha Pavla i ulice Ćirila i Metodija.

\footnotetext{
NAPOMENA:

Ovaj rad proistekao je iz master rada čiji mentor je bio dr Nenad Ruškić.
}

\section{TEORIJSKE OSNOVE}

Saobraćajni tok može biti prost i složen. Prost saobraćajni tok sastoji se od jednog niza vozila koja se kreću u jednom pravcu i u jednom smeru. Složen saobraćajni tok se sastoji od dva ili više prostih saobraćajnih tokova $\mathrm{s}$ obzirom na međusobne odnose nizova.

Nivo usluge je kvalitativni pokazatelj odvijanja saobraćaja na raskrsnici. On se zasniva na utvrđivanju vremenskih zastoja po vozilu za svaku grupu traka i za svaki prilaz, kao i za celu raskrsnicu. Za utvrđivanje nivoa usluge raskrsnica koristi se šestostepena skala sa nivoima usluge od A do F (A najbolji, F najlošiji).

2.1. Osnovni pojmovi o signalisanim raskrsnicama Signalisana raskrsnica predstavlja mesto ukrštanja putnih pravaca $\mathrm{u}$ istom nivou na kojoj je odvijanje saobraćaja regulisano radom svetlosne signalizacije. Programiranjem rada signala na ulaznim grlima raskrsnice, izradom planova vremenske raspodele prava prolaza za sukobljavanje saobraćajnih tokova, vrši se vremenska raspodela prava korišćenja sredine površine raskrsnice.

Regulisanje svetlosnom saobraćajnom signalizacijom je uobičajen način regulisanja saobraćaja na mestima sukobljavanja tokova gde se kao posledica nedostatka kapaciteta za pojedine ili za sve saobraćajne tokove javljaju neopravdano veliki zastoji ili ozbiljnije pogoršava bezbednost saobraćaja.

2.2. Osnovni pojmovi o kružnim raskrsnicama

Projektovanje geometrije savremenih raskrsnica sa kružnim tokom predstavlja traženje kompromisa između kapaciteta i sigurnosti. Raskrsnice sa kružnim tokom funkcionišu sigurnije ukoliko geometrijski elementi uslovljavaju smanjenje prilazne, odnosno, brzine $\mathrm{u}$ kružnom toku. Na- suprot tome, ovakva geometrija uslovljava smanjenje kapaciteta raskrsnice. Takođe mnogi geometrijski elementi uslovljeni su manevarskim sposobnostima najvećeg vozila očekivanog na raskrsnici.

\section{KARAKTERISTIKE ANALIZIRANIH \\ RASKRSNICA}

Raskrsnica Bulevara cara Lazara i ulica Cara Dušana i Ive Andrića u Novom Sadu nalazi se u neposrednoj blizini kružne raskrsnice u koju se ulivaju Bulevar cara Lazara, Bulevar Evrope, Bulevar patrijarha Pavla i Ulica Ćirila i Metodija. Ove raskrsnice predstavljaju frekventnije raskrsnice u gradu s obzirom da se nalaze na lokaciji koja povezuje atraktivne zone grada.

Rastojanje između analiziranih predmetnih raskrsnica 
iznosi oko 168 m. Raskrsnica Bulevara cara Lazara i ulica Cara Dušana i Ive Andrića je četvorokraka signalisana raskrsnica u nivou regulisana svetlosnom saobraćajnom signalizacijom i znacima prioriteta, dok mesto ukrštanja Bulevara cara Lazara, Bulevara Evrope, Bulevara patrijarha Pavla i Ulice Ćirila i Metodija predstavlja kružna raskrsnica sa baj-pas trakama koja je regulisana elementima horizontalne i vertikalne signalizacije kod koje vozila u kružnom toku imaju prednost u odnosu na vozila iz ulivnih pravaca. Izgled analiziranih raskrsnica prikazan je na slici 1 .

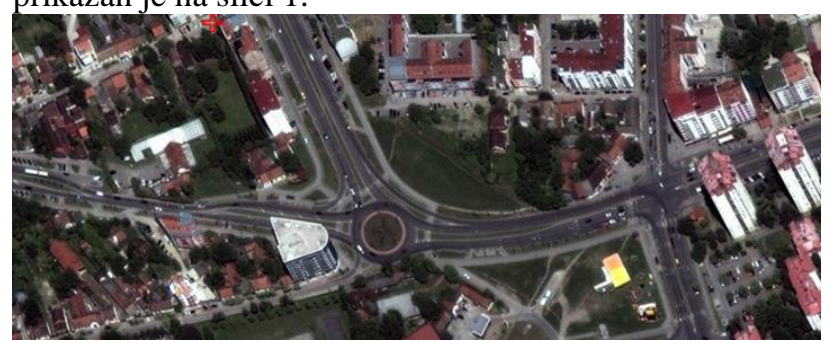

Slika 1. Izgled analiziranih raskrsnica

Analizirane raskrsnice su karakteristične zbog malog rastojanja između njih. Zastoji i zagušenje saobraćaja nastaju na kružnoj raskrnici zbog velikog broja vozila koja privlače dva relativno novoizgrađena bulevara.

Problem nastaje zbog protoka velikog broja vozila koja u vršnom času skreću levo sa Bulevara Evrope i zbog velikog broja vozila koja ih propuštaju, odnosno vozila koja idu pravo sa Bulevara patrijarha Pavla na Bulevar cara Lazara. Povećanje vremena prolaska vozila kroz raskrsnicu dovodi do povećanja vremenskih gubitaka, samim tim i do smanjenja nivoa usluge.

\section{ANALIZA USLOVA ODVIJANJA SAOBRAĆAJA}

Brojanje je izvršeno u utorak, dana 13.06.2017. godine. $\mathrm{Na}$ signalisanoj raskrsnici brojanje je izvršeno $u$ vremenskom intervalu 06:00 - 21:00 časova, dok je na kružnoj raskrsnici izvršeno u više vremenskih intervala tokom istog dana 07:00 - 11:00, 13:00 - 17:00, 18:00 21:00 časova.

Evidentirane su sledeće kategorije vozila: bicikl, motocikl, putnički automobil, autobus, lako teretno vozilo (vozilo do 3,5 tone i teretni kombi), srednje teretno vozilo (vozilo preko 3,5 tone), teško teretno vozilo (tri osovine), autovoz (tegljač i kamioni sa prikolicom).

$\mathrm{Na}$ signalisanoj raskrsnici od ukupnog protoka po prilazima, uočava se da Prilaz 1 ima najmanji protok, zatim Prilaz 3 i Prilaz 2, dok je na Prilazu 4 protok najveći. Ukupno saobraćajno opterećenje, za 15 sati brojanja iznosi 56148 vozila.

Najopterećeniji period funkcionisanja raskrsnice je poslepodnevni vršni period, odnosno period od 16:0017:00 časova, gde je zabeležen protok od 4420 vozila na svim prilazima, dok je najmanja registrovana vrednost saobraćajnog opterećenja registrovana $u$ periodu od 06:00-07:00 časova, gde je ukupan protok vozila sa svih prilaza iznosio 2291 vozila.

Što se tiče strukture toka na analiziranoj signalisanoj raskrsnici, najveći procenat čine putnička vozila sa $96,44 \%$, a zatim autobusi sa $1,51 \%$ i to su uglavnom vozila javnog gradskog prevoza putnika. Teška teretna vozila su zastupljena $0,84 \%$, laka teretna vozila u strukturi toka učestvuju sa $0,78 \%$, srednja teretna vozila učestvuju sa $0,41 \%$. Autovozova ima u najmanjoj meri, svega $0,01 \%$.

Na kružnoj raskrsnici od ukupnog protoka po prilazima, uočava se da prilaz 3 ima najmanji protok, zatim prilaz 1 i prilaz 4, dok je na prilazu 2 protok najveći. Ukupno saobraćajno opterećenje, za 11 sati brojanja iznosi 31410 vozila.

Najopterećeniji period funkcionisanja raskrsnice je poslepodnevni vršni period, odnosno period od 16:00-17:00 časova, gde je zabeležen protok od 3438 vozila na svim prilazima, dok je najmanja registrovana vrednost saobraćajnog opterećenja registrovana u periodu od 09:00-10:00 časova, gde je ukupan protok vozila sa svih prilaza iznosio 2361 vozila.

Što se tiče strukture toka na analiziranoj kružnoj raskrsnici, najveći procenat čine putnička vozila sa 95,06\%, a zatim laka teretna vozila sa $2,05 \%$. Teška teretna vozila su zastupljena $0,96 \%$, dok srednje teretna vozila u strukturi toka učestvuju sa $0,93 \%$. Autobusi čine strukturu sa $0,81 \%$ i to su uglavnom vozila javnog gradskog prevoza putnika. Autovozova ima u najmanjoj meri, svega $0,19 \%$.

\section{PROGNOZA SAOBRAĆAJNOG OPTEREĆENJA}

Razlikujemo postojeće i planirano stanje. Postojeće saobraćajno opterećenje (može se prebrojati) i koristi se za preduzimanje neposrednih akcija u regulisanju saobraćaja.

Prognoza saobraćaja je veoma važna prilikom odabira buduće varijante nekog projekta. Ukoliko se predviđanje saobraćaja ne obavi na pravi način izgrađeni saobraćajni objekat neće moći da zadovolji potrebe za zahtevanim kapacitetom ili će biti predimenzionisan.

$\mathrm{Na}$ osnovu brojanja vršena je prognoza budućeg saobraćaja za narednih 10 godina. Za utvrđivanje rasta saobraćaja su korišćeni podaci iz studije REBIS za Srbiju. Prilikom proračuna, posmatrale su se dve varijante, pesimistička i optimistička. Za utvrđivanje budućeg saobraćaja za pesimističku varijantu je uzet prosečan godišnji rast od $2,5 \%$, dok je za optimističku varijantu uzet prosečan godišnji rast od 3,5\%, u skladu sa preporukama navedene studije.

\section{PREDLOG MERA ZA POBOLJŠANJE USLOVA ODVIJANJA SAOBRAĆAJA NA ANALIZIRANIM RASKRSNICAMA}

Postavljanje varijantnih rešenja i njihova analiza predstavlja jednu od ključnih faza u ovom radu. Cilj ovog rada je da se na osnovu postojećih geometrijskih ograničenja predlože i analiziraju varijante, kako bi se našlo optimalno rešenje za raskrsnice koje su tema rada Radi poboljšanja uslova odvijanja saobraćaja na datoj raskrsnici, predložene su sledeće varijante kao rešenja.

Varijanta 0 - podrazumeva analizu posmatranih raskrsnica pri čemu je zadržana postojeća geometrija, horizontalna i vertikalna signalizacija na obe raskrsnice.

Varijanta 1 - podrazumeva postojeće stanje u smislu geometrije raskrsnice uz dogradnju nadvožnjaka, denivelisanog toka pravo, od Prilaza 4 ka Prilazu 2 analizirane kružne raskrsnice, odnosno na prilazu Bulevara patrijarha Pavla i Bulevara cara Lazara. 
Izgled Varijante 1 raskrsnice dat je na slici 2.

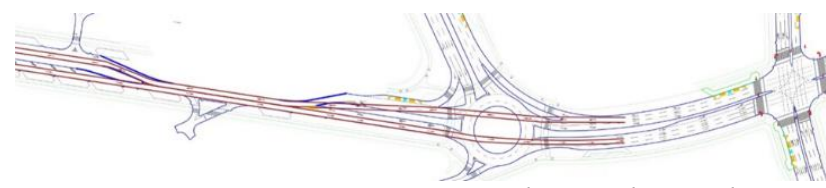

Slika 2. Prikaz Varijante 1 - Dogradnja nadvožnjaka na kružnoj raskrsnici

Varijanta 2 - podrazumeva kompletnu rekonstrukciju kružne raskrsnice, menjanje njene geometrije i projektovanje četvorokrake signalisane raskrsnice umesto analizirane kružne raskrsnice i određene geometrijske izmene na postojećoj signalisanoj raskrsnici.

Novoprojektovana raskrsnica Bulevara cara Lazara, Bulevara Evrope, Bulevara patrijarha Pavla i Ul. Ćirila i Metodija bi predstavljala četvorokraku raskrsnicu u nivou regulisanu svetlosnom saobraćajnom signalizacijom i znacima prioriteta. Na narednoj slici je prikazan izgled rekonstruisane kružne raskrsnice u signalisanu raskrsnicu.

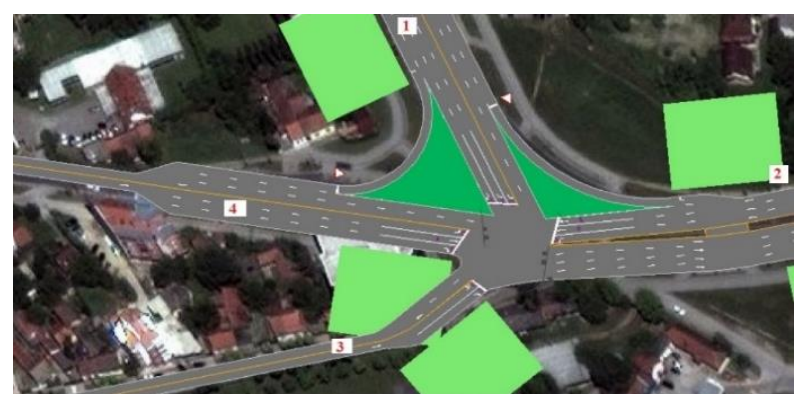

Slika 3. Prikaz Varijante 2 - Rekonstrukcija kružne raskrsnice Bulevara cara Lazara, Bulevara Evrope, Bulevara patrijarha Pavla i Ul. Ćirila i Metodija

Uz pomoć softverskog programa Synchro 10 dobijena je i optimalna dužina ciklusa koja iznosi 110 sekundi i na osnovu toga, predviđena je i fazna podela.

Kod postojeće signalisane raskrsnice Bulevara cara Lazara i ulica Cara Dušana i Ive Andrića predlaže se izgradnja dodatnih traka $\mathrm{u}$ skladu sa prostornim mogućnostima.

Na narednoj slici je prikazan izgled signalisane raskrsnice Bulevara cara Lazara i ulica Cara Dušana i Ive Andrića sa izmenama koje su predložene.

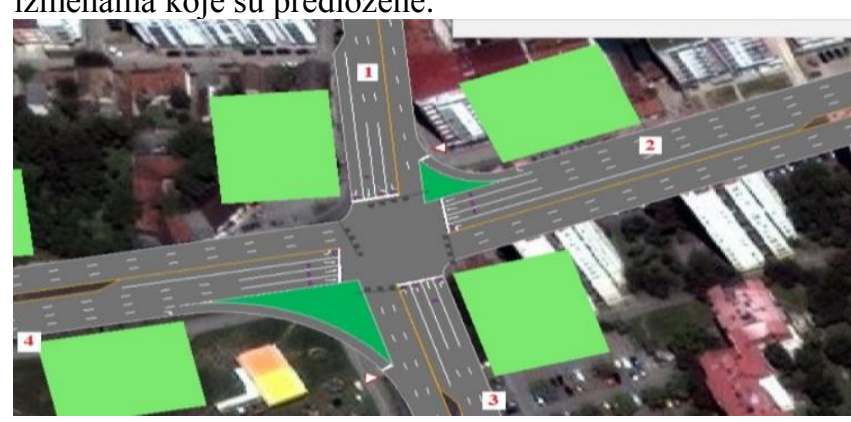

Slika 4. Prikaz Varijante 2 - Predložene izmene na raskrsnici Bulevara cara Lazara i ulica Cara Dušana $i$ Ive Andrića

$\mathrm{Na}$ osnovu predloženih varijanti, metodom proračuna, odrediće se koja je varijanta najbolja za analizirane raskrsnice, odnosno koja obezbeđuje najbolje uslove za nesmetano odvijanje saobraćaja, čime se smanjuju ili eliminišu redovi čekanja, što će i smanjiti vremenske gubitke $i$ povećati nivo usluge na obe raskrsnice. Posmatramo i uzimamo optimistički prognozirani desetogodišnji period kao nepovoljnije i realno stanje.

\section{VREDNOVANJE PREDLOGA MERA ZA POBOLJŠANJE USLOVA ODVIJANJA SAOBRAĆAJA}

\subsection{Funkcionalno vrednovanje predloženih mera}

Funkcionalno vrednovanje vršeno je uz pomoć softverskog paketa Synchro 10, koji je namenjen za proračun kapaciteta i nivoa usluge na raskrsnicama.

$\mathrm{Za}$ potrebe izrade ovog rada, u program su unete karakteristike analiziranih raskrsnica, za svaku varijantu ponaosob. U nastavku je data uporedna analiza dobijenih vrednosti. Prikazani su vremenski gubici i nivo usluge za svaku varijantu po raskrsnicama.

Tabela 1. Prikaz vremenskih gubitaka i nivoa usluge na analiziranim raskrsnicama

\begin{tabular}{|c|c|c|c|c|c|c|}
\hline \multicolumn{7}{|c|}{ Bulevar cara Lazara- ul. Cara Dušana-ul. Ive Andrića } \\
\hline $\begin{array}{l}\text { Nivo } \\
\text { usluge }\end{array}$ & Varij. & $\begin{array}{c}\text { Prilaz } \\
1\end{array}$ & $\begin{array}{c}\text { Prilaz } \\
2\end{array}$ & $\begin{array}{c}\text { Prilaz } \\
3\end{array}$ & $\begin{array}{c}\text { Prilaz } \\
4\end{array}$ & Raskrsnica \\
\hline Optim. & Varij. 0 & $\begin{array}{c}195,8 \\
(\mathrm{~F})\end{array}$ & $\begin{array}{c}114,7 \\
\text { (F) }\end{array}$ & $\begin{array}{c}149,6 \\
\text { (F) }\end{array}$ & $\begin{array}{c}183,4 \\
(\mathrm{~F})\end{array}$ & $155,5(F)$ \\
\hline varijanta & Varij.1 & $\begin{array}{c}238,3 \\
(\mathrm{~F})\end{array}$ & $\begin{array}{c}114,7 \\
(\mathrm{~F})\end{array}$ & $\begin{array}{c}110,2 \\
(\mathrm{~F})\end{array}$ & $\begin{array}{c}182,9 \\
(\mathrm{~F})\end{array}$ & 152,7 (F) \\
\hline 2027 & Varij. 2 & $\begin{array}{c}60,1 \\
(\mathrm{E})\end{array}$ & $\begin{array}{c}93,6 \\
(\mathrm{~F})\end{array}$ & $\begin{array}{l}52,8 \\
\text { (D) }\end{array}$ & $\begin{array}{l}31,8 \\
(\mathrm{C})\end{array}$ & $60,0(E)$ \\
\hline
\end{tabular}

Bulevar patrijarha Pavla-Bulevar Evrope-Bulevar cara Lazara-ul. Ćirila i Metodija

\begin{tabular}{|c|c|c|c|c|c|c|}
\hline & & & & & & \\
\hline $\begin{array}{l}\text { Nivo } \\
\text { usluge }\end{array}$ & Varij. & $\begin{array}{c}\text { Prilaz } \\
1\end{array}$ & $\begin{array}{c}\text { Prilaz } \\
2\end{array}$ & $\begin{array}{c}\text { Prilaz } \\
3\end{array}$ & $\begin{array}{c}\text { Prilaz } \\
4\end{array}$ & Raskrsnica \\
\hline Optim. & Varij. 0 & $\begin{array}{c}40,8 \\
(\mathrm{E})\end{array}$ & $6,5(\mathrm{~A})$ & $25,0(\mathrm{C})$ & $\begin{array}{c}130,5 \\
\text { (F) }\end{array}$ & 43,9 (E) \\
\hline varijanta & Varij. 1 & $\begin{array}{l}11,3 \\
\text { (B) }\end{array}$ & $0,4(\mathrm{~A})$ & $5,0(\mathrm{~A})$ & $\begin{array}{c}13,8 \\
\text { (B) }\end{array}$ & $4,1(A)$ \\
\hline 2027 & Varij. 2 & $\begin{array}{l}84,5 \\
(\mathrm{~F})\end{array}$ & $\begin{array}{l}49,3 \\
\text { (D) }\end{array}$ & $38,4(\mathrm{D})$ & $\begin{array}{l}16,4 \\
\text { (B) }\end{array}$ & 48,9 (D) \\
\hline
\end{tabular}

$\mathrm{Na}$ osnovu podataka iz prethodne tabele može se zaključiti da je kod Varijante 2 zabeleženo najpovoljnije funkcionalno rešenje, koje je koordinacijom signalnih planova praćeno smanjenjem vremenskih gubitaka na obe rasrsnice koji iznose 60,0 (s/voz) odnosno, 48,9 (s/voz). Kao što i rezultati pokazuju, najlošiji nivo usluge na obe raskrsnice utvrđen je u Varijanti 0 što znači da je na kraju prognoziranog desetogodišnjeg perioda neophodno preduzeti neke mere.

7.2. Ekonomsko vrednovanje predloženih mera $\mathrm{Za}$ potrebe rekonstrukcije, analizirane su vrednosti građevinskih intervencija, pratećih građevinskih radova $\mathrm{i}$ postavljanja signalizacije za predložene varijante. U tabeli 2. dat je prikaz troškova izgradnje za svaku varijantu.

Tabela 2. Troškovi izgradnje

\begin{tabular}{|c|c|}
\hline Varijanta & Troškovi izgradnje \\
\hline Varijanta 0 & $0,00 €$ \\
\hline Varijanta 1 & $3.500 .000,00 €$ \\
\hline Varijanta 2 & $320.000,00 €$ \\
\hline
\end{tabular}

$\mathrm{Na}$ osnovu podataka iz predhodne tabele i ekonomske analize sa aspekta izgradnje, zaključuje se da je Varijanta 0 najisplativija, zbog minimalnih troškova izgradnje. Ova varijanta ne podrazumeva rekonstrukciju ili izvođenje 
radova, i shodno tome, izostaju i pomenuti troškovi. Posmatrajući ostale varijante, najnepovoljnija je Varijanta 1 koja ima očekivano visoke troškove izgradnje.

$\mathrm{U}$ benefit-cost analizi, pored troškova izgradnje, uzimamo u obzir troškove goriva koji nastaju zaustavljanjem vozila na raskrsnici.

Vremenski gubici koji se javljaju na raskrsnici su u direktnoj vezi sa potrošnjom goriva i zagađenjem vazduha. Usled većih vremenskih gubitaka na raskrsnici, raste i potrošnja goriva, a samim tim i zagađenje vazduha. Ako su uslovi odvijanja saobraćaja na višem nivou usluge, potrošnja goriva je niža, kao i zagađenje vazduha. U narednoj tabeli predstavljeni su troškovi goriva prilikom zaustavljanja vozila po varijantama.

Tabela 3. Troškovi goriva prilikom zaustavljanja vozila $u$ $€$ u 10-godišnjem periodu za varijante

\begin{tabular}{|c|c|}
\hline Varijanta & Troškovi goriva $(\boldsymbol{\epsilon})$ \\
\hline Varijanta 0 & $7.129 .980,79$ \\
\hline Varijanta 1 & $6.550 .475,65$ \\
\hline Varijanta 2 & $4.313 .165,27$ \\
\hline
\end{tabular}

\subsection{Ekološko vrednovanje predloženih mera}

Usled nepotpunog sagorevanja u motorima, zaostaju kapljice goriva i ulja, i javljaju se štetni gasovi. Tri značajna izduvna gasa, koja će biti razmatrana u analizi jesu:

$$
\begin{array}{ll}
\text { - } & \mathrm{CO}_{2}-\text { ugljen-dioksid; } \\
\text { - } & \mathrm{N}_{2} \mathrm{O}-\text { azot-suboksid; } \\
& \mathrm{CH}_{4} \text { - metan. }
\end{array}
$$

U narednoj tabeli dati su troškovi zagađenja vazduha.

Tabela 6. Troškovi zagađenja vazduha usled potrošnje goriva

\begin{tabular}{|c|c|c|c|c|}
\hline Varijanta & $\mathbf{C O 2}(\boldsymbol{f} / \mathbf{t})$ & $\mathbf{N 2 O}(\boldsymbol{f}$ t) & $\mathbf{C H 4}(\mathbf{f} / \mathbf{t})$ & Ukupno $(\boldsymbol{f}$ t) \\
\hline Varijanta 0 & $33.148,91$ & 565,97 & 985,82 & $\mathbf{3 4 . 7 0 0 , 7 0}$ \\
\hline Varijanta 1 & $30.454,65$ & 519,97 & 905,70 & $\mathbf{3 1 . 8 8 0 , 3 2}$ \\
\hline Varijanta 2 & $20.052,89$ & 852,23 & 10,14 & $\mathbf{2 0 . 9 1 5 , 2 7}$ \\
\hline
\end{tabular}

\subsection{Ukupni troškovi predloženih mera}

U narednoj tabeli dati su ukupni troškovi po varijantama. Tabela 3. Ukupni troškovi po varijantama

\begin{tabular}{|c|c|c|c|c|}
\hline \multirow{2}{*}{ Varijanta } & $\begin{array}{c}\text { Troškovi } \\
\text { goriva }(\boldsymbol{\epsilon})\end{array}$ & $\begin{array}{c}\text { Troškovi } \\
\text { izgradnje } \\
(\boldsymbol{\epsilon})\end{array}$ & $\begin{array}{c}\text { Troškovi } \\
\text { zagađenja } \\
(\boldsymbol{\epsilon})\end{array}$ & Ukupno $(\boldsymbol{\in}) \mathbf{t )}$ \\
\hline Varijanta 0 & $7.129 .980,79$ & 0,00 & $34.700,70$ & $\mathbf{7 . 1 6 4 . 6 8 1 , 4 9}$ \\
\hline Varijanta I & $6.550 .475,65$ & $3.500 .000,00$ & $31.880,32$ & $\mathbf{1 0 . 0 8 2 . 3 5 5 , 9 7}$ \\
\hline Varijanta 2 & $4.313 .165,27$ & $320.000,00$ & $20.915,27$ & $\mathbf{4 . 6 5 4 . 0 8 0 , 5 4}$ \\
\hline
\end{tabular}

$\mathrm{Na}$ osnovu tabele ukupnih troškova, zaključuje se da Varijanta 1 predstavlja najnepovoljniji slučaj sa preko 10 miliona $€$ troškova. Varijanta 2 se izdvojila kao varijanta sa najnižim ukupnim troškovima.

\section{ZAKLJUČAK}

Nakon definisanja osnovnih karakteristika raskrsnice, sledi prikaz rezultata dobijenih brojanjem. Brojanje je vršeno 13.06.2017. godine. Na signalisanoj raskrsnici je kao vršni sat dobijen period od 16:00-17:00 časova gde je izbrojano 4420 vozila dok je na kružnoj raskrsnici dobijen vršni period od 16:00-17:00 časova gde je zabeležen protok od 3438 vozila.
Za analizu u daljem radu uzeta je optimistička varijanta rasta broja vozila. Za narednih 10 godina, očekivani broj vozila u vršnom satu za signalisanu raskrsnicu iznosi 6235 vozila, dok za kružnu raskrsnicu iznosi 4850 vozila. $\mathrm{Na}$ osnovu prognoze saobraćaja izvršena je analiza nivoa usluge.

U okviru Poglavlja 6 date su varijante predloženih rešenja, i to:

$$
\text { - } \quad \text { Varijanta } 0 \text { - Postojeće stanje }
$$$$
\text { nadvožnjaka na kružnoj raskrsnici }
$$

- Varijanta 2 - Četvorokraka signalisana raskrsnica umesto kružne raskrsnice $i$ izmena signalnog plana na postojećoj signalisanoj

Nakon definisanih predloga mera, izvršeno je njihovo funkcionalno, ekonomsko i ekološko vrednovanje.

Prema analizi ukupnih troškova može se zaključiti da je optimalno i najracionalnije usvojiti Varijantu 2.

Varijanta 2, odnosno izgradnja četvorokrake signalisane raskrsnice umesto kružne raskrsnice, izdvaja se kao najpovoljnije tehničko rešenje koje bi uticalo na poboljšanje uslova odvijanja saobraćaja na analiziranim raskrsnicama. Koordinacija signalisanih raskrsnica ostvaruje manje vremenske gubitke, daje bolji novo usluge, izdvaja se kao jeftinije rešenje sa aspekta troškova gradnje i ima veću uštedu $\mathrm{u}$ troškovima eksploatacije $\mathrm{u}$ odnosu na Varijantu 1.

\section{LITERATURA}

1] (2010). Highway Capacity Manual. The National Academies

[2] (2000). Highway Capacity Manual. The National Academies

[3] http://www.putevi-srbije.rs. (n.d.)

[4] Kuzović, Lj. (1994). Vrednovanje u upravljanju razvojem i ekploatacijom putne mreže. Beograd: Saobraćajni fakultet.

[5] Kuzović, Lj. (2000). Kapacitet i nivo usluga drumskih saobraćajnica. Beograd: Saobraćajni fakultet.

[6] Kuzović, Lj.,Bogdanović, V. (2010). Teorija saobraćajnog toka. Novi Sad: Fakultet tehničkih nauka.

[7] Pravilnik o saobraćajnoj signalizaciji. ("Sl. Glasnik RS", br. 134/2014)

\section{Kratka biografija:}

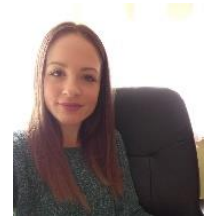

Jelena Marković rođena je u Novom Sadu 1993. god. Master rad na Fakultetu tehničkih nauka iz oblasti Saobraćaj i transport, na smeru Projektovanje i organizacija odbranila je 2020.god.

Kontakt: jelenna93@gmail.com 